\title{
Preliminary Steady State and Dynamic Analysis of a MicroGrid System
}

\author{
A. Madureira, C. Moreira and J. Peças Lopes \\ Faculty of Engineering of Porto University and Power Systems Unit of INESC Porto \\ Rua Dr. Roberto Frias, 378, 4200-465 Porto, Portugal \\ Phone:+351 22 2094000, Fax:+ 35122 2094050, E-mail: agm@inescporto.pt, cmoreira@inescporto.pt, jpl@fe.up.pt
}

\begin{abstract}
The objective of this paper is to analyse the steady state and dynamic behaviour of a MicroGrid system containing one microturbine generating Combined Heat and Power feeding some small local loads in islanded mode of operation. Future operating scenarios were also analysed and simulated, namely considering the installation of photovoltaic panels near consumers.
\end{abstract}

\section{Keywords}

Dispersed Generation, Dynamic Behaviour, Microturbine, Steady State Analysis

\section{Introduction}

The connection of microgeneration to Low Voltage (LV) networks is starting to be considered as an interesting technical option. This is due to the fact that there is a pressing need to reduce and control $\mathrm{CO}_{2}$ emissions. Furthermore, pollution, atmosphere and soil degradation and hydro resource's exhaustion and other environmental issues are becoming major concerns in modern societies, which lead to the search for new and more efficient forms of electricity generation.

Accordingly, urgent measures must be taken in order to allow the reduction of Green-House Gases emissions and motivate the use of renewable power resources. These two factors are part of the objectives of the European Energy Policy.

An important contribution may be given by the connection of microgeneration considering, for instance, the investment in photovoltaic panels, wind parks, small hydro's, microturbines and fuel cells, both of these intended for Combined Heat and Power (CHP) applications. These technologies allow local renewable resources to be explored and contribute to increase global efficiency when using fossil fuels. In addition, microgeneration may also contribute to increase reliability to final consumers, respond to power quality issues and also help to improve system operation by reducing active power losses and enhancing voltage profiles.

A re-regulation phenomenon has also been changing power system operation paradigms in terms of management and control. The next years will testify new changes due to the advent of the connection of microgeneration to the LV distribution network.

The main objective of this paper is to analyse the steady state and dynamic behaviour of a study case LV network, located in Portugal.

\section{Portuguese Study Case Low Voltage Network}

This study case LV network comprises a microcogeneration system based on a microturbine, which generates both electric power and heat in a Natural Gas (NG) station. The microturbine is a Turbogen TG80RC$\mathrm{G}$ manufactured by Bowman Power. The microturbine has a single-shaft design and it has an electrical power output of $80 \mathrm{~kW}$. This LV network is located in Frielas, a small village in the Lisbon suburbs, Portugal and belongs to EDP (Portuguese Distribution Utility).

A potential operation scheme is depicted in Fig. 1, where it is possible to observe the distribution transformer (PTD), the microturbine plant and an LV feeder with its electrical loads. The consumers are mainly of the industrial, residential and agricultural type [1]. In a near future it is expected that photovoltaic panels (PV) may be installed at some customers $(\mathrm{C} 3, \mathrm{C} 12$, and $\mathrm{C} 14)$.

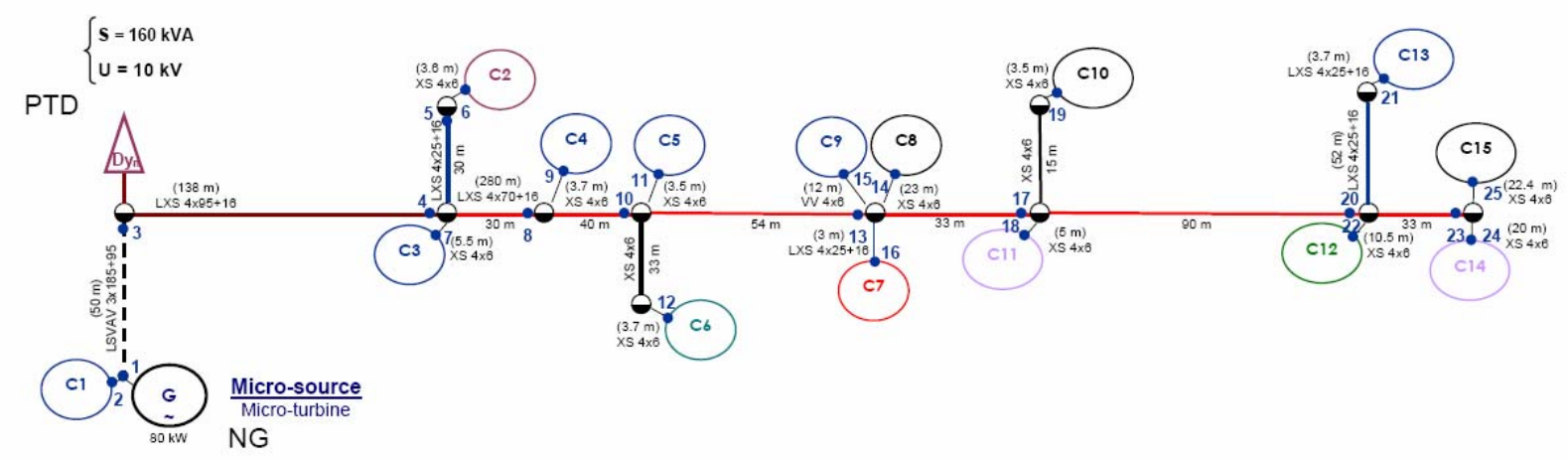

Fig. 1. Scheme of the EDP LV study case network [1] 
More details on the electrical data and consumers' characterisation can be found in [1].

Regarding the specific characteristics of this microcogeneration system [1], two operation scenarios can be defined for this electrical grid:

- Normal Interconnected Mode: the LV distribution system is interconnected with the upstream MV network and the microturbine is running at full power, and the corresponding electric power produced is consumed locally in the LV grid and the remaining power is exported to the MV network;

- Autonomous Operation Mode: due to planned or unplanned situations (maintenance needs, faults) in the upstream MV network, the LV system can be operated autonomously (islanded operation). In this case, microturbine production will be continuously adapted to the LV grid load. Currently, the microturbine has the capacity to supply all of the 15 LV consumers represented in Fig. 1 [1].

The owner EDP has performed several tests on this electrical system and the main measurements recorded are presented in [1]. One of the tests performed consisted in moving to islanded operation mode. Initially the microturbine is operating at full power and then the loss of mains is tested. In the actual micro-cogeneration plant, the microturbine feeds only a small protected load $(\mathrm{C} 1)$ during islanded conditions.

According to the normal operation plan defined for the microturbine, an imbalance of at least $50 \%$ of the microturbine rated power is foreseen between the generated power and the LV grid load. Recorded measurements can be found for imbalances of about 90 to $95 \%$, which lead to very high over-voltages (around 1.6 p.u.) and with a significant time duration. These overvoltages may damage LV loads and it will be desirable to smoothen the transitions to autonomous operation by installing some form of storage device at the LV side of the distribution transformer. The storage device should be a fast acting power source able to absorb or inject active power in a matter of a few seconds and could be a flywheel system or a super-capacitor. In this case, a loss of mains detection will lead to the islanding of the LV system and the Voltage Source Inverter (VSI) associated with the storage device will ensure that the microturbine will be able to operate stably in islanded mode. In this operation mode, the microturbine static converter will act as a current source. Also, some reactive power capacity should be included in order to guarantee some margin for an efficient voltage control.

A local load-frequency control function should also be installed in the microturbine in order to control its active power production according to load variations and in order to maintain the MicroGrid frequency within tight limits [2]. Primary voltage and frequency control are performed by the VSI. Details on this control approach can be found in [3].

\section{Simulation Platform}

The study case LV network used for simulation purposes and the corresponding simulation platforms under the MatLab ${ }^{\circledR}$ Simulink ${ }^{\circledR}$ environment are presented next. The system under analysis was transposed to the simulation platform under the MatLab ${ }^{\circledR}$ Simulink ${ }^{\circledR}$ environment developed within the MicroGrids Project [3], as can be seen in Fig. 2.

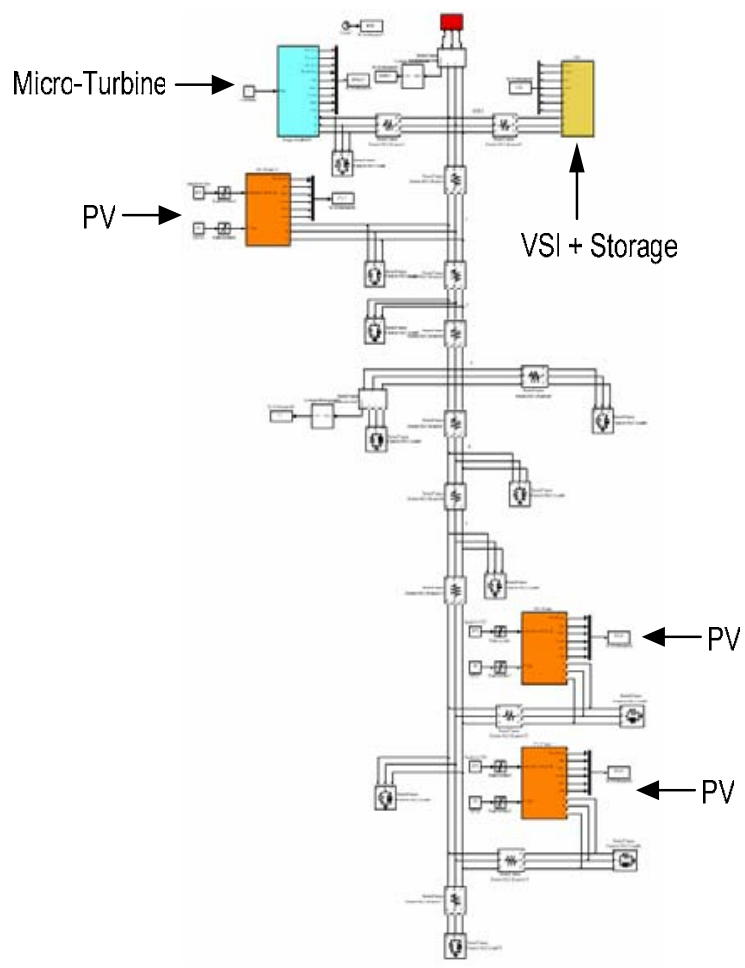

Fig. 2. EDP LV study case network under the MatLab ${ }^{\circledR}$ Simulink ${ }^{\circledR}$ environment

Adequate dynamic models for all sources including the microturbine, PV panels, storage devices and power electric interfaces were developed and used. More details on modelling issues can be found in [4] and [5] for the dynamic models used in this study.

\section{Steady State Analysis}

In order to evaluate the steady state behaviour of the study case network, a power flow algorithm was used. The tool used for the power-flow calculation was MatPower ${ }^{\circledR}$, a toolbox for MatLab ${ }^{\circledR}$ [6].

The network scheme used is presented in Fig. 1.

A steady state analysis was performed for two scenarios:

- Scenario 1 included an islanded operation, with the microturbine feeding all MicroGrid loads; 
- Scenario 2 included also an islanded operation, with the MicroGrid loads being fed by the microturbine and by 3 PV panels.

The main objective of this analysis is to compare the behaviour of the MicroGrid in terms of voltage profiles and power losses.

TABLE I - Power losses in the two scenarios considered

\begin{tabular}{|l|c|c|}
\cline { 2 - 3 } \multicolumn{1}{c|}{} & \multicolumn{2}{c|}{ Losses (\%) } \\
\cline { 2 - 3 } \multicolumn{1}{c|}{} & $\mathrm{P}$ & $\mathrm{Q}$ \\
\hline Scenario 1 & 2.16 & 3.35 \\
\hline Scenario 2 & 1.42 & 1.79 \\
\hline
\end{tabular}

From Table I it can be seen that there is a reduction in both active and reactive power losses in the case of the inclusion of dispersed PV panels. The PV units help to minimize the losses by generating active and reactive powers locally.

Also, the PV panels included also contribute to voltage control since they inject reactive power with a power factor of $\cos (\varphi)=0.93$.

In terms of voltage deviations from specified values, the second scenario presents a maximum improvement of $1.44 \%$ when compared to the first scenario. All voltages are well within acceptable limits for both scenarios.

\section{Dynamic Analysis}

Several simulations were performed that involved mainly the passage to islanded operation and load-following. Some results from the dynamic simulation will be presented next.

The dynamic behaviour of the this study case LV network was evaluated after disconnecting the MV network for the two different scenarios (Scenario 1 and Scenario 2) presented in the previous section.
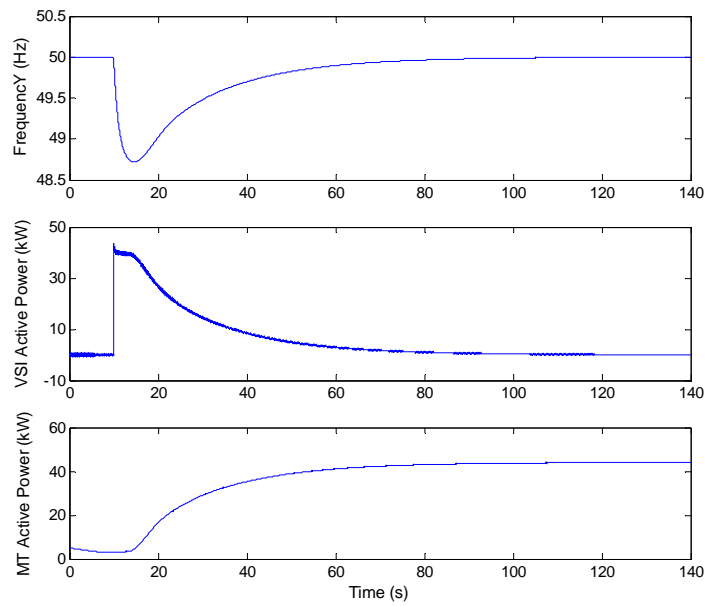

Fig. 3. MicroGrid frequency and microturbine active and reactive powers (Scenario 1)
Considering Scenario 1 the MicroGrid is importing around $45 \mathrm{~kW}$ and $10 \mathrm{kvar}$ from the upstream MV network, with a local generation of $4 \mathrm{~kW}$ and $10 \mathrm{kvar}$ and a MicroGrid load of $49 \mathrm{~kW}$ and 20 kvar.

The islanding of the MG occurs at $\mathrm{t}=10 \mathrm{~s}$ and the main results may be seen in Fig. 3.

From Fig. 3 it can be seen that the frequency is safely restored to its nominal value of $50 \mathrm{~Hz}$ and stability is not lost in the transition to islanded operation. It can also be seen that the active and reactive powers compensate the load/generation imbalance.

Considering Scenario 2 the MicroGrid is exporting around $39 \mathrm{~kW}$ to the upstream MV network and importing 12 kvar from the upstream MV network, with a local generation of $88 \mathrm{~kW}$ and $8 \mathrm{kvar}$ and a MicroGrid load of $49 \mathrm{~kW}$ and $20 \mathrm{kvar}$.

The disconnection of the MV network occurs at $t=10 \mathrm{~s}$ and the main results are shown in the following figures.


Fig. 4. MicroGrid frequency and microsources' active power (Scenario 2)
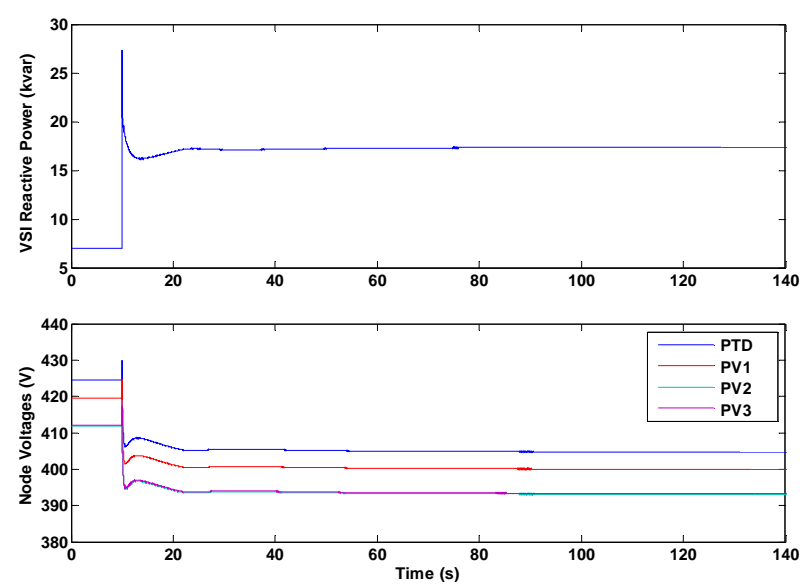

Fig. 5. VSI reactive power and voltages at the secondary side of the PTD and at the PV panels (Scenario 2) 
As it can be observed in Fig. 4, the high imbalance between MicroGrid load and generation is quickly compensated by the VSI coupled with the storage device, which absorbs the excess of power produced in the MT, while a secondary control loop (included in this model) reduces MT active power production in order to match local load and maintain frequency around the nominal value of $50 \mathrm{~Hz}$.

The VSI is responsible for controlling voltage in the islanded MicroGrid. The presence of the VSI smoothes the transition to islanded operation and no significant over-voltages are observed (as can be seen in Fig. 5).

\section{Conclusions}

In this paper steady state and dynamic stability studies developed for an EDP Portuguese study case LV network were described.

Regarding the steady state analysis, no very significant improvements regarding system operation in terms of voltage are achieved, because the main microsource (i.e., the microturbine) is installed at the beginning of the feeder and the power production at the PV panels is fairly low. Nevertheless, a small improvement of system losses can be obtained when considering the PV units connected to the system and also an enhancement in the power factor is achieved.

Regarding the analysis of the dynamic behaviour, the suggestion of installing a storage device at the LV side of the distribution transformer is an effective way to smooth the transition from grid-connected mode to islanded operation mode, as proved by the results obtained. Also, islanding is well succeeded in both importing and exporting conditions.

\section{Acknowledgement}

The authors wish to thank the European Commission (EC) for financial support within the framework of European Union (EU) Project "MicroGrids" under Contract No. ENK-CT-2002-00610.

The authors also would like to thank the contribution made by António Amorim and Nuno Melo from EDP for the work presented in this paper.

\section{References}

[1] A. Amorim, A. L. Cardoso, J. Oyarzábal and N. Melo, "Analysis of the Connection of a Microturbine to a Low Voltage Grid", in Proceedings International Conference on Future Power Systems FPS 2005, Amsterdam, The Netherlands.

[2] A. Madureira, C. Moreira, J. Peças Lopes, "Secondary Load-Frequency Control for MicroGrids in Islanded Operation", in Proceedings International Conference on Renewable Energy and Power Quality ICREPQ’05, Zaragoza, Spain.
[3] J. Peças Lopes, J. Tomé Saraiva, N. Hatziargyriou and N. Jenkins, "Management of MicroGrids", in Proceedings Jornadas Internacionales de Equipos Eléctricos JIEEC2003, Bilbao, Spain.

[4] J. A. Peças Lopes, C. L. Moreira and A. G. Madureira, "Defining control strategies for analysing microgrids islanded operation", in Proceedings IEEE St. Petersburg PowerTech 2005, St. Petersburg, Russia.

[5] N. Hatziargyriou et al., "Modelling of Micro-Sources for Security Studies", in Proceedings CIGRÉ 2004 Conference, Paris, France.

[6] MatPower: A Matlab Power System Simulation Package.

Available: http://www.pserc.cornell.edu/matpower/ 